\title{
Exploring the potential of palynology in archaeological contexts: proceedings of the session held at the 24th Annual Meeting of the European Association of Archaeologists in Barcelona 2018
}

\author{
Jutta Lechterbeck ${ }^{1}\left[\right.$. Christin E. Jensen ${ }^{1}$
}

Received: 28 January 2020 / Accepted: 31 January 2020 / Published online: 10 February 2020

(c) Springer-Verlag GmbH Germany, part of Springer Nature 2020

Pollen analysis is a recognized method for the detection and interpretation of past environmental changes caused by climate variability and human action. The objects of research are often natural archives such as lakes and mires because they usually provide the best preservation conditions and are less disturbed by direct anthropogenic influences, therefore rather recording environmental changes in the surroundings. On-site pollen analysis in contrast can provide direct information on human activity, which often played a major role in the formation of the pollen assemblage as well as the deposit, thus having a great potential, as numerous studies since the 1980s have shown.

Plant macrofossils in aerobic sediments are preserved mainly in charred state and reflect as such human activity. Instead, pollen grains are preserved as uncharred microfossils, and reflect local and/or regional environmental conditions. Their analysis is therefore suitable for addressing questions of land use as well as on-site activities, like food processing, plant deposition in graves, etc. We believe that the method is still underrepresented in archaeological projects and its full potential is thus not fully reached. Therefore, we organized a session at the 2018 meeting of the EAA dealing with a broad spectrum of contributions e.g. the analysis of on-site material including non-pollen palynomorphs, combined pollen and macrofossil analyses, combined on-site and off-site studies, as well as experimental and present-day studies on pollen dispersal and deposition with reference to land use and other activities.

The session was well received and included a wide variety of topics ranging from the possibility of recovering

Communicated by F. Bittmann.

Jutta Lechterbeck

jutta.lechterbeck@uis.no

1 Museum of Archaeology, University of Stavanger, Peder Klows gate 31A, PB 8600 Forus., 4036 Stavanger, Norway pollen grains from hearths and artefacts, research on pollen and non-pollen palynomorphs from waste deposits and their contribution to studies of diet, to on-site studies of sediments from a lake site village and from soil profiles. A clear focus, however, lay on the study of wells, where the preservation conditions for pollen are usually excellent. Nevertheless, questions of preservation and preservation biases were intensely discussed-in fact preservation seems to be the key issue with regards to on-site palynology.

In this special section of the present issue, five of the papers given in the session are presented; three of them deal with wells, one with lake sediments and one with the geoarchaeological investigation of a fortification.

Lagerås and Fredh used well deposits from southern Sweden as pollen archives for landscape reconstruction and applied the landscape reconstruction algorithm to these data. The algorithm has never before been applied to such heavily human-influenced spectra, but the authors could convincingly show that the method gives meaningful results. This method might thus be used for other well deposits, especially in landscapes which otherwise lack suitable pollen archives.

Van Amerongen, on the other hand, points out in her paper that data obtained from wells and off-site data in Westfriesland, the Netherlands, can give conflicting results on the type and amount of regional vegetation. She discusses the nature and potential of well deposits, and how the use of wells and their position in a settlement might affect the pollen assemblages.

Stobbe et al. present a multidisciplinary case study of a Roman well in Germany. The well is exceptional as several phases of use are preserved by the sediment layers, which accumulated during the occupation of the Roman town. Consequently, the sediment record reflects various types of activities around the well.

Sobkowiak-Tabaka et al. present results from a very thorough multidisciplinary study of lake sediments closely connected to a Mesolithic hunter-gatherer site. They succeed in 
showing how the environment around the site was affected by human activities and contribute to increasing knowledge about Mesolithic hunter-gatherers in western Poland in general.

Gumnior et al. investigated a large fortified Bronze Age settlement in Romania, combining on-site pollen analysis with geomorphological and pedological methods. They are furthermore able to compare on-site to off-site data convincingly.

On the whole, the session showed that by asking new questions and taking new viewpoints, the innovative potential of a well known and established method such as pollen analysis can be developed-which is also reflected in the contributions of this special section.

Publisher's Note Springer Nature remains neutral with regard to jurisdictional claims in published maps and institutional affiliations. 